\title{
Adolescent health literacy: factors effecting usage and expertise of digital health literacy among universities students in Pakistan
}

Adnan Adil ${ }^{1 *}$, Ahmed Usman $^{2}$, Nasir Mehmood Khan ${ }^{3}$ and Faria Ibad Mirza ${ }^{4}$

\begin{abstract}
Background: Electronic health tools are of little use if the intended user lacks the skills to effectively engage them. Engaging eHealth requires a skill set, or literacy, of its own. The present study is an effort to probe the relationship of education and Institution (Independent Variables) with the usage and expertise in eHealth literacy (Dependent Variables) among university students. The research is conducted in 16 Higher Education Commission (HEC) Pakistan's recognized universities in Lahore. Both male and female students ranging from BS to PhD programs were the focus of the research.
\end{abstract}

Methods: Quantitative data was collected through survey method using stratified random sampling technique. There were different kinds of strata in population i.e. general universities, health sciences universities, engineering universities and animal sciences universities etc. The research encompassed a total of 89,664 students in 16 universities, from which sample size of 1513 was drawn through research advisor table (2006). Proportional allocation formula was used to specify the number of respondents from each university. Non-parametric statistics was used since data was not normally distributed. Kruskal-Wallis $\mathrm{H}$ test and Mann-Whitney $\mathrm{U}$ test were applied to measure the difference of effect of groups of independent variables on the dependent variables.

Results: The level of using digital health literacy was not same for all students, as the students of PhD and BS/ Masters were significantly different from each other in terms of their usage of digital health literacy. Level of education showed a significant influence on level of expertise in eHealth literacy, confirming that changing the level of education had an effect on level of expertise in digital health literacy, but the size of effect was smaller. MS/ MPhil and PhD students were significantly different from each other in their expertise in digital health literacy.

Conclusion: Results of the study depicted that belonging to different categories of educational levels differently affect the level of usage and that of expertise in digital health literacy among university students.

Keywords: eHealth, Digital health literacy, University students, Usage of electronic health

\footnotetext{
* Correspondence: adnanadil8787@gmail.com

'Institute of Social \& Cultural Studies, University of the Punjab, Lahore,

Pakistan

Full list of author information is available at the end of the article
}

(c) The Author(s). 2021 Open Access This article is licensed under a Creative Commons Attribution 4.0 International License, which permits use, sharing, adaptation, distribution and reproduction in any medium or format, as long as you give appropriate credit to the original author(s) and the source, provide a link to the Creative Commons licence, and indicate if changes were made. The images or other third party material in this article are included in the article's Creative Commons licence, unless indicated otherwise in a credit line to the material. If material is not included in the article's Creative Commons licence and your intended use is not permitted by statutory regulation or exceeds the permitted use, you will need to obtain permission directly from the copyright holder. To view a copy of this licence, visit http://creativecommons.org/licenses/by/4.0/. The Creative Commons Public Domain Dedication waiver (http://creativecommons.org/publicdomain/zero/1.0/) applies to the data made available in this article, unless otherwise stated in a credit line to the data. 


\section{Background}

Digital health literacy (DHL) denotes the level to which individuals have the capability to contact, rehearsal, and grasp the elementary health knowledge, and amenities essential to make apt health judgments while using electronic resources [1]. DHL is developing as a significant concept that can upshot into outstanding optimistic vicissitudes in health. It was espoused by industrialized nations first, and nowadays the emerging nations are also making efforts to fit-in it into their health system [2]. According to the reports of 'Pew Internet and American Life Project', the world population is increasing at the pace of $1.4 \%$ per annum, while technology users are growing at the pace of 7.9\% per annum. This gap depicts that inclination towards adoption of advanced technologies is becoming an ideal source of getting knowledge [3].

The practice of using android cell phones and other such components had also paved the ways to get online health information. According to the statistics of 'Pew Internet', $52 \%$ percent smart android mobile users had surfed for online health knowledge through their mobiles for more than one time. Other statistics of 'Pew Internet' further illustrate that 10 out of 100 persons are consuming internet, and out of these 10 personages, seven individuals falls under the definition of youth [3], whereas as per the statistics of Ministry of Youth Affairs, Pakistan (2017) [4], approximately one third part of population belongs to youth segment. Findings from the previous studies advocates that apprentices, scholars, and patients etc. can be characterized as the recipients of the digital health knowledge [5]. Practice of these ehealth properties is greatly influenced by gender [6], internet access, level of education, and technical support in usage of e-resources [7]. Dickerson et al., [8] depicted the association of level of education and ethnicity of patients, with online health literacy. The patients were divided into two diverse groups i.e. who attended college, and who didn't. They made conclusion that the patients, who had appeared in college, had a better level of practice in digital health literacy, whereas the patients, who had not attended college in their life, had lower level of usage of online health literacy. The study of Fogel et al., [9] came-up with the same findings, depicting the association of education and income, with DHL. Similarly, the logitudinal study of Flynn et al., [10] pointed out a positive association between higher level of education and online health literacy.

The contextual understanding of the literature depicted that ICTs usage was associated with level of education. The present study intended to probe the factors associated with ICTs usage in searching health. The present study hypothesized that the level of education is associated with (1) level of usage and (2) level of expertise in digital health literacy among university students in Pakistan.

\section{Methods}

For the present study, there is a single categorical independent variable (level of education) having three categories i.e. BS/Masters, MPhil and $\mathrm{PhD}$, while there are two continuous dependent variables i.e. level of usage and level of expertise in digital health literacy. Level of usage of digital health literacy was measured with a scale of 6 items, using a four point Likert scale from 1 = "very often" to 4 = "never", and level of expertise in digital health literacy was measured with a scale of 6 items, using a four point Likert scale from $1=$ "strongly disagree" to 4 = "strongly agree".

The study was conducted in Lahore, Pakistan, as there are number of public and private sector universities located in the city. According to HEC list 2013, there are 16 public and private sector universities in Lahore [11]. There were four different types of universities in Lahore i.e. general universities, health sciences universities, engineering universities and animal sciences universities.

Stratified random sampling was employed for the selection of respondents as the categories in our population were heterogeneous. The sub population within an overall population varied. The total number of students in 16 universities was 89,664 (As depicted in Table 1). Sample size $(n=1513)$ was calculated through Research Advisor Table 2006 [12], while keeping 95\% confidence interval and $2.5 \%$ margin of error. Formula of proportionate allocation determined the number of respondents from each stratum.

$$
n i=n\left(\frac{N i}{N}\right)
$$

\section{Where:}

$n i=$ sample size for each stratum, $n=$ sample size, $N i$ = Stratum Size, $N=$ Population Size.

Respondents completed a self-report questionnaire [13] containing scales measuring expertise and usage level of digital health literacy. Respondents were also asked questions regarding their educational level, time spent on computer and type of institution. Face validity and factor analysis were used to measure the validity of data collection tool. Face validity means to what extent it looks like to measure the desired thing [14]. For this purpose, many teachers including $\mathrm{PhD}$ supervisor, were consulted. To measure the validity, factor analysis was also performed. While measuring the components of data collection tools, approximately all the components fell in the level of I component extraction, which declared the validity of data collection tool. Then value of Alpha (value of $\boldsymbol{\alpha}>0.7$ ) declared the reliability of the instrument. The value of alpha $(\alpha)$ was obtained through 
Table 1 University wise allocation of sample

\begin{tabular}{|c|c|c|c|}
\hline Strata & Universities Name & Students in Selected University & Selected Students in Sample \\
\hline & University of South Asia, Lahore & 1171 & 20 \\
\hline & University of Management and Technology, Lahore & 3308 & 56 \\
\hline & University of Lahore, Lahore & 11,461 & 193 \\
\hline & University of Central Punjab, Lahore & 4237 & 71 \\
\hline & Minhaj University, Lahore & 1464 & 25 \\
\hline & Lahore University of Management Sciences & 2356 & 40 \\
\hline & Hajvery University, Lahore & 2758 & 47 \\
\hline & Beaconhouse National University, Lahore & 1178 & 20 \\
\hline & University of Education, Lahore. & 10,369 & 174 \\
\hline & University of the Punjab, Lahore & 24,961 & 421 \\
\hline & Government College University, Lahore & 7438 & 125 \\
\hline & Lahore College for Women University & 4582 & 77 \\
\hline \multirow[t]{2}{*}{ Health sciences } & King Edward Medical University & 1826 & 31 \\
\hline & University of Health Sciences, Lahore & 156 & 4 \\
\hline Engineering & University of Engineering and Technology & 9399 & 158 \\
\hline Animal Sciences & University of Veterinary and Animal Sciences & 3000 & 51 \\
\hline Total & 89,664 & & 1513 \\
\hline
\end{tabular}

checking cross-product deviations and covariance in SPSS.

\section{Results}

Statistics of Table 2 are depicting that total number of the respondents was 1513. Majority of students i.e. 1269 (83.9\%) belonged to general universities, while 51 (3.4\%) were from animal sciences universities, 158 (10.4\%) from

Table 2 Descriptive Analysis for Socio-Cultural Variables

\begin{tabular}{lll}
\hline Socio-Cultural Characteristics & Frequency & Percentage \\
\hline Type of Institution & & \\
Animal Sciences Universities & 51 & 3.4 \\
General & 1269 & 83.9 \\
Engineering & 158 & 10.4 \\
Health Sciences & 35 & 2.3 \\
Total & 1513 & 100 \\
Education & & \\
Bs/Masters & 730 & 48.2 \\
Ms./Mphil & 679 & 44.9 \\
PhD & 104 & 6.9 \\
Total & 1513 & 100.0 \\
Time Spent on Computer & & \\
0-1 & 28 & 1.9 \\
2-3 & 468 & 30.9 \\
4-5 & 658 & 43.5 \\
6=> & 359 & 23.7 \\
Total & 1513 & 100.0 \\
\hline
\end{tabular}

engineering universities, and 35 (2.3\%) respondents were from health sciences universities. Similarly, 730 (48.2\%) students were in their BS/Masters degree, 679 (44.9\%) in MS/MPhil degree and 104 (6.9\%) in PhD degree.

Furthermore, the data is also elaborating that 28 (1.9\%) respondents were spending 0 to $1 \mathrm{~h}$ daily on computer, while $468(30.9 \%)$ respondents were spending 2 to $3 \mathrm{~h}$ daily on computer. A significant number of respondents $658(43.5 \%)$ was spending 4 to $5 \mathrm{~h}$ daily on computer, while 359 (23.7) percent respondents were spending 6 or more hours on computer daily. Data is showing that approximately $75 \%$ of the respondents were spending 2 to $5 \mathrm{~h}$ daily on computers.

\section{Statistical analysis for hypothesis 1}

Data in Table 3 is depicting the association between level of education and level of usage of digital health literacy. The independent variable was categorical having three different educational groups i.e. M.A, MPhil., and $\mathrm{PhD}$, while dependent variable was continuous. The purpose was to observe whether changing the level of education had an effect on the level of usage of digital

Table 3 Relationship between Level of Education and Level of Usage of Digital Health Literacy

\begin{tabular}{lll}
\hline & Education & Mean Rank \\
\hline Level of Usage & BS/Masters & 763.09 \\
& MS/M.Phil. & 771.22 \\
& PhD & 621.37 \\
\hline
\end{tabular}

Test Statistics: Chi- Square: 11.003, df: 2, P. value: .004 
health literacy among students or not? The statistics Kruskal-Wallis $\mathrm{H}$ test depicted a gap in the means rank (621 to 771), which strengthened the argument that means of different levels of education were different for level of using digital health literacy. P. value (.004) rejected the null hypothesis and concluded that the students belonging to different classes had different level of usage in digital health literacy.

The value of Dunn test value (0.28) (chi-square value (11.003) was divided by $\sqrt{n}$ (Under root sample size) depicted a medium size of effect by independent variable on the dependent variable.

Data in Table 4 is depicting the test statistics of Mann-Whitney U test. The data showed that students of $\mathrm{PhD}$ and BS/Masters were significantly different from each other in the usage of digital health literacy. Similarly, PhD students were also significantly different from MS/MPhil students in level of usage of digital health literacy. Such findings concluded that level of usage of digital health literacy was different among students of different classes.

\section{Statistical analysis for hypothesis 2}

Data in Table 5 is depicting the effect of categorical independent variable (level of education) on the continuous dependent variable (level of expertise in digital health literacy). The aim was to examine whether changing the level of education had an effect on level of expertise in digital health literacy or not? Kruskal-Wallis $\mathrm{H}$. test statistics depicted a gap in the mean ranks (682 to 782), authenticating that changing the level of education had an effect on level of expertise in digital health literacy. P. Value (.044) also rejected the null hypothesis.

Dunn test value (0.1) (Chi-square value (6.250) was divided by $\sqrt{n}$ ) depicted a smaller size of effect of independent variable on the dependent variable. It was estimated that the level of expertise was affected by the level of education, but at a smaller level. To analyze, which groups of independent variable were affecting the dependent variable differently, Mann-Whitney $U$ test was applied. For this purpose, groups of Independent variables were categorized pair-wise. Then each pair's effect was analyzed against the dependent variable.

Data in Table 6 shows that MS/MPhil and PhD students were significantly different from each other in

Table 4 Mann-Whitney U Tests for Level of Education and Level of Usage of Digital Health Literacy

\begin{tabular}{lll}
\hline & Level of Education & P-Value \\
\hline Level of Usage & BS / Master - MS / M.Phil. & .695 \\
& BS / Masters - PhD & .001 \\
MS / M.Phil. & .002 \\
\hline
\end{tabular}

Table 5 Relationship between Level of Education and Level of Expertise in Digital Health Literacy

\begin{tabular}{lll}
\hline & Education & Mean Rank \\
\hline Level of Expertise & BS/Masters & 743.48 \\
& MS/M.Phil. & 782.98 \\
& PhD & 682.26
\end{tabular}

Test Statistics: Chi- Square: 6.250, df: 2, P. value: .044

their level of expertise in digital health literacy that authenticated the argument that students belonging to different levels of education were different in level of expertise in digital health literacy.

\section{Discussion}

In contrast to previous researches, the present research included a larger sample in order to examine the factors effecting usage and expertise of digital health literacy among students. In addition to finding the relationship between independent and dependent variable, the present study investigated the relative difference within the categories of independent variable during their effect on the dependent variable.

In line with previous researches, the findings of the present study found that the level of usage of digital health literacy was different among the students of different educational categories. Students of $\mathrm{PhD}$ and BS/ Masters were significantly different from each other in terms of their usage of digital health literacy. In the same manner, $\mathrm{PhD}$ students were also significantly different from MS/MPhil students in terms of their level of usage of digital health literacy. Previous studies suggested similar results. The study of Wangberg et al., [7] investigated the relationship between education and subjective health information; education was found to be more closely related to subjective health information. Similarly, Matsuyama et al., [15] pointed out the affiliation of education of patients with digital health literacy. They concluded that the patients who attended college in their life had higher use of technology for accessing health information as compared to those who did not attend the college. Similarly, Fogel et al., [9] examined the occurrence and predictors of internet use for medical information among women with breast cancer. They found that patients with higher education or income, and patients of white race were more likely to use the internet for breast

Table 6 Mann-Whitney U Test for Level of Education and Level of Expertise in Digital Health Literacy

\begin{tabular}{lll}
\hline & Level of Education & P-Value \\
\hline Level of Expertise & BS/ Masters - MS / MPhil & .088 \\
& BS / Masters - PhD & .180 \\
& MS / MPhil - PhD & .026 \\
\hline
\end{tabular}


cancer related health issues. Flynn et al., [10] tried to understand how and when patients use non-physician sources of health. It was concluded that years of education were associated with searching online for health information. Similarly, James et al., [16] examined cancer patients' and carers' use of, and attitudes towards, the internet as a health information source. The use of internet information was uniformly low among ethnic minorities and was uniformly high among educated patients.

The present research complements previous researches by highlighting the association between level of education and level of expertise in digital health literacy. It is found that MS/MPhil and PhD students are substantially dissimilar to each other in their level of expertise in digital health literacy. Similar results were drawn by Birru et al., [17]; they concluded that low literacy may come across as an informational hurdle on the internet when searching for health information because most health related web sites necessitate at least a high-school reading proficiency for best possible access. Similarly, Gustafson et al., [18] reviewed different reports of comprehensive Health Enhancement Support System (CHES $\mathrm{S}$ ) and concluded that the higher level of education was required to benefit from digital health literacy. Once again, same kind of unexpected results emerged as increasing or decreasing the level of education did not increase or decrease the level of expertise in digital health literacy. However, it was found through values of mean ranks that the usage and the expertise level in digital health literacy are positively associated.

The limitations of the present study propose guidelines for future research. It would be interesting to extend this study to other contexts or institutions of education. It is also important to extend the research by including other related variables such as students' age, gender, and ICT expertise etc. The current study could only collect data from the university students of different disciplines and institutions. The future studies should focus to produce results in a larger scenario including school and college students. It is furthermore suggested that the validity of the present study can be enhanced by taking the opinion of students having some kind of permanent disease.

\section{Conclusion}

This study found that there is an association between the level of education and the levels of (1) usage and (2) expertise in digital health literacy. Students of diverse educational levels had diverse levels of usage and expertise in the digital health literacy. On the basis of findings, the study concludes that educational level is the major factor for unequal response towards digital health literacy. The study furthermore depicted that the students of BS/Master, MS/MPhil and PhD are substantially different from each other in their level of usage and expertise in digital health literacy. The findings of the present research can play a vital role in narrowing health inequalities. The study may also provide guidelines to health policy makers by indicating that the educational level can promote general health searching tendencies among the general masses.

\section{Abbreviations \\ DV: Dependent Variable; DHL: Digital health literacy; HEC: Higher Education Commission; IV: Independent Variable; ICTs: Information and Communication Technologies}

\section{Acknowledgments}

We want to thank all the students who participated in this study.

\section{Authors' contributions}

All authors read and approved the final manuscript. AA. Literature Review, Developed Questionnaire, Worked on Methodology, Data Collection, Data Analysis, Miscellaneous Activities. AU. Language and Grammar Correction, Data Collection, Data Editing, Data Analysis, Miscellaneous Activities. NMK. Data Collection, Data Editing, Data Analysis, Miscellaneous Activities. FIM. Data Collection, Data Analysis.

Funding

This research does not involve any funding.

Availability of data and materials

The datasets used during the current study are available from the corresponding author on reasonable request.

\section{Ethics approval and consent to participate}

The ethical approval was granted for the study by Ethics Committee of Doctoral Program at University of the Punjab Lahore, Pakistan (1516/Acad. R. No. 1288/ISCS). The study participants were informed about the research aim and methods before signing the informed consent form.

\section{Consent for publication}

Not Applicable.

\section{Competing interests}

The Authors declare that they have no competing interests.

\section{Author details}

${ }^{1}$ Institute of Social \& Cultural Studies, University of the Punjab, Lahore, Pakistan. ${ }^{2}$ Sociology, Institute of Social \& Cultural Studies, University of the Punjab, Lahore, Pakistan. ${ }^{3}$ PMAS Arid Agriculture University, Rawalpindi, Pakistan. ${ }^{4}$ Lecture Sociology, PMAS Arid Agriculture University, Rawalpindi, Pakistan.

Received: 29 January 2020 Accepted: 15 December 2020

Published online: 09 January 2021

References

1. Norman CD, Skinner HA. eHEALS: The eHealth literacy scale. J Med Internet Res. 2006;8(4):e27. https://doi.org/10.2196/jmir.8.4.e27. http://www.jmir.org/2 006/4/e27/v8i4e27 [PMCID: PMC1794004] [PubMed: 17213046]. Accessed 2 Mar 2019

2. Venkatesh $V$, Sykes TA. Digital divide initiative success in developing countries: a longitudinal field study in a village in India. Inf Syst Res. 2013. 24(2):239-60.

3. Madden M, Lenhart A, Duggan M, Cortesi S, Gasser U. Teens and technology 2013. Washington DC: Pew Research Center's Internet \& American Life Project; 2013.

4. Tarar MA, Khan YN, Ullah MZ, Salik MH, Akhtar S, Sultan T. Knowledge and attitude; pregnancy and antenatal care among young agrarian \& nonagrarian females in Faisalabad District, Pakistan. Pak J Agric Sci. 2019;56(1).

5. Sorensen T. Health trends WHO/eHealth consumer trends survey 2005, presentation at joint meeting of the SANCO health systems working party and the INFSO eHealth working group, Luxemburg. 2005. 
6. Atkinson N, Saperstein S, Pleis J. Using the internet for health-related activities: findings from a national probability sample. J Med Internet Res. 2009;11(1):e5.

7. Wangberg SC, Andreassen HK, Prokosch HU, Santana SMV, Sørensen T, Chronaki CE. Relations between internet use, socio-economic status (SES), social support and subjective health. Health Promot Int. 2008;23(1):70-7.

8. Dickerson S, Reinhart AM, Feeley TH, Bidani R, Rich E, Garg VK, Hershey CO Patient internet use for health information at three urban primary care clinics. J Am Med Inform Assoc. 2004;1 1 (6):499-504.

9. Fogel J, Albert SM, Schnabel F, Ditkoff BA, Neugut Al. Use of the internet by women with breast cancer. J Med Internet Res. 2002;4(2):e9.

10. Flynn KE, Smith MA, Freese J. When do older adults turn to the internet for health information? Findings from the Wisconsin longitudinal study. J Gen Intern Med. 2006;21(12):1295-301.

11. Universities (2013): Retrieved from: http://www.hec.gov.pk/Pages/HECMain. aspx. Accessed 2 Mar 2019.

12. Research Advisor (2006): Retreived from http://www.research-advisors.com/ tools/SampleSize.htm. Accessed 2 Mar 2019.

13. Karnoe A, Kayser L. How is eHealth literacy measured and what do the measurements tell us? A systematic review. Knowledge Manage E-Learn. 2015;7(4):576-600.

14. Drost EA. Validity and reliability in social science research. Educ Res Perspect. 2011;38(1):105.

15. Matsuyama RK, Lyckholm LJ, Molisani A, Moghanaki D. The value of an educational video before consultation with a radiation oncologist. J Cancer Educ. 2013;28(2):306-13.

16. James N, Daniels H, Rahman R, McConkey C, Derry J, Young A. A study of information seeking by cancer patients and their careers. Clin Oncol. 2007; 19:356-62.

17. Birru MS, Monaco VM, Charles L, Drew H, Njie V, Bierria T, Steinman RA. Internet usage by low-literacy adults seeking health information: an observational analysis. J Med Internet Res. 2004;6(3):e25.

18. Gustafson DH, Hawkins RP, Boberg EW, McTavish F, Owens B, Wise M, Pingree S. CHESS: 10 years of research and development in consumer health informatics for broad populations, including the underserved. Int J Med Inform. 2002;65(3):169-77.

\section{Publisher's Note}

Springer Nature remains neutral with regard to jurisdictional claims in published maps and institutional affiliations.

Ready to submit your research? Choose BMC and benefit from:

- fast, convenient online submission

- thorough peer review by experienced researchers in your field

- rapid publication on acceptance

- support for research data, including large and complex data types

- gold Open Access which fosters wider collaboration and increased citations

- maximum visibility for your research: over $100 \mathrm{M}$ website views per year

At $\mathrm{BMC}$, research is always in progress.

Learn more biomedcentral.com/submissions 